\title{
Relations between play skills and mathematical skills in toddlers
}

\author{
Elin Reikerås ${ }^{1} \mathbb{0}$ \\ Accepted: 29 January 2020 / Published online: 8 February 2020 \\ (c) The Author(s) 2020
}

\begin{abstract}
Play is central to children's learning and development in the early years, including the learning of mathematics. The aim of the present study was to explore how play skills are related to mathematical skills in toddlers by examining the correlations between different kinds of play skills and mathematical skills, and how level of play skills is related to mathematical skills. The participants were 1088 toddlers in Norwegian Early Childhood and Care institutions who were observed by the staff in 3 -month periods beginning when they were $2 \frac{1}{2}$ years old. The skills in mathematics and play were assessed by structured observation. The overall scores for play skills and the scores for all types of play skills correlated significantly with the scores for all mathematical areas and the total score for mathematics. The skills Interaction in Play and Independence in Play displayed the strongest correlations with mathematical skills. Rule-based Play was difficult for the toddlers, whereas Pretend Play and Exploring and Construction Play correlated with mathematical skills and may be types of play that are more suitable when introducing mathematics in toddler groups. When the group of toddlers was divided into three subgroups according to their level of play skills, the level of play skills was strongly related to the level of mathematical skills. Toddlers with weak, middle or strong play skills also exhibited corresponding low, medium or high levels of mathematics skills, which emphasises the importance of understanding the relations between play and mathematical learning when working with toddlers.
\end{abstract}

Keywords Toddlers $\cdot$ Mathematical skills $\cdot$ Types of play skills $\cdot$ Relations between play and mathematics $\cdot$ Authentic assessment

\section{Introduction}

Play is essential in the lives of young children, as it is important for their well-being, development and learning (Pellegrini et al. 2007); in addition, play has value in itself (Samuelsson and Carlsson 2008). Several studies have confirmed that children already before the age of three (toddlers) learn mathematics through play (e.g., Björklund 2008; Reikerås et al. 2012). Knowledge about the development of play skills in children has received increasing attention (Hännikäinen and Munter 2018). However, knowledge about the relations between play skills and skills in mathematics in toddlers is still lacking. Knowledge of these possible relationships may be important when planning mathematical activities with young children. The aim of the present study was to explore this relation between play skills and mathematical skills in toddlers. As a part of this goal, it will be

Elin Reikerås

elin.reikeraas@uis.no

1 The University of Stavanger, Stavanger, Norway investigated whether any particular play skills in toddlers display a greater correlation with mathematical skills than others and how the level of play skills is related to mathematical skills.

\section{Background}

\subsection{Play and learning}

Although there are different views on what play is, most researchers agree that play is fun, voluntary, flexible, inner motivated, without extrinsic goals, involves active engagement, and commonly has elements of make-believe (e.g., Fisher et al. 2011; Lillard et al. 2013; Pellegrini et al. 2007; Sutton-Smith 2009). There are also different views on the particular role play have in learning, and in learning activities such as mathematics, in an Early Education and Care (ECEC) context. Some researchers placed an equal sign between play and learning for young children (e.g., Golinkoff et al. 2006), whereas other researchers, such as 
Samuelsson and Johansson (2006), noted that play and learning are not the same, but they are dimensions that stimulate each other and should be viewed as an indivisible entirety.

Play has many facets (Sutton-Smith 2009), and views on play differ according to culture (Fleer 2014), which affects how play is viewed as part of the pedagogy. Different views of play are not only a theoretical discussion in the research community but are also mirrored in the beliefs and practices of ECEC-teachers (Bubikova-Moan et al. 2019; Wood 2010). Synodi (2010) describes three main approaches to play as part of the pedagogical work in ECEC institutions (ECECs), namely, free play, teacher-organised play and mutual directed play. In free play, also called childinitiated play, the children are allowed to play without any direct interference from the teachers, and these activities take place both outdoors and indoors (Sundsdal and Øksnes 2015). The children have power and control over the play and the teacher acts as an observer and listener (Wood 2013). In teacher-organised play, also called guided play or structured play, the teacher sets the rules and initiates the play (Synodi 2010). In this type of play, the teacher often uses play to achieve specific learning goals, and play often adopts the form of games (Hassinger-Das et al. 2018). The third approach Synodi mentions is mutual directed play, in which the teacher gets involved in children's free play in a nondisruptive manner (Henry 1990). The teachers then respect the children's play and become involved under the children's conditions (Wood 2013). As a co-player, the teacher has a role in the children's play and can enrich the play, and the teacher thus scaffolds the children's learning and play (Synodi 2010). Mutual directed play is the opposite of teachers' interrupting the children's play and taking control of the play in order to teach rules or concepts in the curriculum (Henry 1990).

Depending on the culture, each of the three categories is included and emphasised to varying degrees (Synodi 2010; Ødegaard and $\mathrm{Hu}$ 2019). For example, in the playful learning tradition used in the USA (Hirsh-Pasek et al. 2009), which also includes free play, teacher-guided play has been emphasised to a greater extent than the Nordic tradition in which free play traditionally dominates (Jensen 2009). At the policy level, an understanding of the relation between play and learning is visible in the curriculum for the ECECs (Synodi 2010; Ødegaard and Hu 2019. In an analysis of the new curricula for the ECECs in Norway for children aged 1-5 years (The Directorate of Education and Training 2017), in which context the present study was based, play received increasing attention in the curriculum. However, a trend has been observed towards a shift from emphasising children's own play to adopting a more learning-based view in Norway (Ødegaard and Hu 2019). In this curriculum, the relation between play and learning is stated as follows: Play shall be an arena for the children's development and learning and for social and linguistic interaction (p. 20).

In the part of the Norwegian curricula regarding mathematics, play, experimentation and investigation are mentioned as the working methods (p. 53). The approaches used in the pedagogical work with mathematics in the ECECs was not examined in the present study. However, the research and views on the relations between play and learning constitutes an important background for studying the relationship between play skills and mathematical skills in toddlers.

\subsection{Toddlers mathematics}

Although most research on young children's mathematics has been conducted with children aged 4 years and older, the knowledge of how even younger children learn and develop mathematics skills has accumulated (MacDonald and Murphy 2019). Beginning at birth, children explore their surroundings to make sense of them and set things in order (Björklund 2008). The child's exploration of and interaction with his or her surroundings involves many mathematical concepts that give the child valuable mathematical experience from which he or she learns (Solem and Reikerås 2017). Upon reaching the toddler age, the child shows skills in a broad field of mathematics, such as in numbers and quantitative thinking, geometry and problem solving (Reikerås et al. 2012). In the present study, these different aspects of the mathematics are considered.

Typical quantitative skills developed during the toddler age include making judgements of 'more', distinguishing between one and many, obtaining knowledge of number words and making bijections (Reikerås et al. 2012). The different quantitative components appear to develop as separate skills before they are combined; however, the understanding of the role of units in the numerical representation of quantities is rarely functional until several years later (Mix et al. 2002).

At the toddler age, children develop geometrical skills as recognition of shapes by classifying and naming objects (Sarama and Clements 2009), spatial knowledge that is necessary when playing with blocks (Casey et al. 2008), puzzlemaking skills by recognising parts of shapes and putting the parts together (Montford and Readdick 2008), and experience with patterns and by producing their own patterns (Seo and Ginsburg 2004).

Toddlers can reason and draw logical conclusions if the task is motivating and the context is familiar (English 2004), and children use many strategies to solve problems (Chen and Siegler 2000). The toddlers' logical reasoning and problem-solving skills are mainly expressed through action, since their language skills are not yet fully developed (Björklund 2008). 


\subsection{Types of play}

The present study focuses on some key play skills central in the ECECs. Although the toddlers' play is categorised into different types of play and play skills in the present study, these categories are not strictly separated. Play is a complex, continuously changing activity, and the toddlers might smoothly alternate between the different types of play (Hännikäinen and Munter 2018). The different play types are also present in several forms in the different pedagogical approaches (Synodi 2010) described above. For example, pretend play is often associated with free play, as well as exploration and construction play, and rule-based play can be initiated by the children. Similar associations have been observed for teacher-initiated play. An argument for the differentiation of the different types of play is present in the description of the play skills.

\subsubsection{Exploring and construction play}

Both sensorimotor play and functional play are included in exploratory play. In these types of play, the child uses all the senses to test the function of toys and objects in his/ her surroundings, and this type of play is a central type in the first 2 years of life of a child (Hännikäinen and Munter 2018). Sensorimotor play stimulates the sensory or motor system and is characterised by several repetitions of banging, throwing, opening, shutting, emptying, and exploring toys (Manning and Wainwright 2010). Through experimentation with objects and toys, the child obtains valuable experience for the development of his or her mathematical skills (Solem and Reikerås 2017). Examples include the exploration and classification of geometric forms and their functions, e.g., the ball rolls, whereas the block does not. As the toddlers experiment with their surroundings in sensorimotor play, they start by not only exploring the environment with objects, but also use them as they are intended; their play is functional (Manning and Wainwright 2010).

Construction with building blocks such as wood bricks and DUPLO blocks is a common play activity for toddlers. Play and construction with building blocks challenges skills related to space and shape (Casey et al. 2008), and play with blocks is also linked to quantitative skills and mathematical language (Schmitt et al. 2018).

\subsubsection{Pretend play}

Pretend play is often considered the highest form of play and is defined as "true" play in some of the literature (e.g., Vygotskij 1978). This form of play is also called imaginative play, make-believe play, sociodramatic play and role-play (Bodrova and Leong 2015). Pretend play is in one sense the mature form of play, at its highest level between 3 and
6 years of age (Jing and Li 2015), whereas the prerequisites for this type of play emerge in the first 3 years of age (Hännikäinen and Munter 2018). According to Engel (2005), toddlers in the beginning of their second year use pretend play to differentiate the worlds of everyday-lived reality (what is) from an alternative pretend sphere known as the world of what if.

Physically active play such as rough-and-tumble play (R\&T) contains elements of pretend play (Storli and Sandseter 2015). The children 'pretend' e.g. to be superheroes when running, climbing and play fighting. Roughand-tumble play emerges from the age of two and increases throughout childhood (Lindsey 2014).

The imagination of a 2-year-old differs from that of a 3 -year-old. A 2-year-old child is able to pretend that a block is a telephone, whereas a toy car, which has a clear function, cannot be used as a telephone (Lillard 1993). By the age of three, the child has developed further skills in symbolisation; the toy car can now represent a telephone (ibid.). The ability to abstract and symbolise, as occurs in pretend play, is a central skill in mathematics. For example, when counting, the understanding of both three dolls and three cars is symbolised by the word 'three' and is crucial in the quantitative development of the child (Solem and Reikerås 2017).

In pretend play, the child operates in a zone of proximal development where learning and development occur (Bodrova and Leong 2015; Vygotskij 1978). Pretend play also provides rich opportunities for mathematical learning (Worthington and van Oers 2016). However, more research is needed on the relations between cognitive development (such as in mathematics) and pretend play (Lillard et al. 2013).

\subsubsection{Rule-based play}

Some types of play are rule-based and have specific goals, such as board games, hide-and-seek, computer games, ball games, etc. Researchers generally agree that rule-based play, such as games, stimulates cognitive development; however, this has been found only in children aged 4 years and older (Lai et al. 2018). Some of the rule-based games are developed for toddlers, such as Lotto, simple puzzles, and some computer games. Toddlers can participate in some of the more advanced rule-based play together with other children if the rules are not too complicated and the other participants are slightly flexible about the rules and the goal of the play. For the youngest children, the goal is to have fun rather than to follow the rules. Rule-based play in the form of board games and computer games is an engaging way of working with mathematics together with young children (Ramani et al. 2019) and can promote the learning of mathematics (Cohrssen and Niklas 2019; Vogt et al. 2018). However, the adults engaging in the play have an important role in 
determining the mathematical outcome (Ramani and Scalise 2018).

\subsection{General play skills}

\subsubsection{Independence in play}

In addition to skills related to different types of play, more general play skills are needed, and an example of this type of skill is independence in play. Typically, toddlers play alone in parallel to each other by observing and imitating each other's actions (Hännikäinen and Munter 2018). The abilities to show initiative and to engage in solitary play and parallel play represent independence in play and are important play skills in toddler age (Meland et al. 2019). In this type of play, the toddler obtains important experiences with mathematics (Solem and Reikerås 2017), and children who take the initiative and participate to a greater extent in this type of play may attain an advantage in mathematics over children who participate to a lesser extent. The ability to stay in play also reflects the toddler's independence in play to some extent and is related to self-regulation. Self-regulation skills have been found to be related to mathematical skills (Becker et al. 2014).

\subsubsection{Interaction in play}

Play is a social process, and skills in interaction are an important play skill. Toddlers are social actors with social competences who may adopt others' perspectives and use negotiating skills during their play (Engdahl 2011). Toddlers most frequently use nonverbal communication as actions to communicate since their verbal language is not yet extensively developed (Björklund 2008). Locomotion, gestures, physical actions and facial expressions are the most common types of communication toddlers use to invite others to play, negotiate in play, and close play sessions (Engdahl 2011). Regarding learning, including mathematics, the interaction of toddlers with their surroundings is very important (Vygotskij 1978). Additionally, skills included in play with others such as turn-taking require both an understanding of order and self-regulation, both of which, as noted, are related to mathematical skills.

\subsection{Level of play skills and the relation to mathematical skills}

Toddlers' skills in mathematics are important for their 'here and now' life, their play and daily activities (Solem and Reikerås 2017). Additionally, these skills lay the foundation for children's further mathematical development in their early years (Claessens et al. 2009). High quality work with mathematics in the ECECs is very important, particularly for children with a weak foundation (Clements et al. 2014). In the ECECs, play is highly focused, and the relation between the level of play skills and the strength of language skills in toddlers has been reported (Stangeland 2017). Toddlers also learn many mathematics skills through play (Reikerås et al. 2012); however, researchers have not yet determined whether the level of skills in play mirrors the level of skills in mathematics.

\subsection{Research question}

The present study aim to answer the main research question

How are the play skills of toddlers related to their mathematical skills?

This question is answered by

(a) Examining the correlation between the total play skills and mathematical skills, including both the total score for mathematics and scores for different mathematical skills,

(b) Identifying whether particular play skills in toddlers exhibit stronger correlations with mathematical skills than others, and what mathematical skills correlate with play skills, and

(c) Determining how the level of play skills is related to the level of mathematical skills in toddlers.

\section{Design and method}

The present study is part of the longitudinal Stavanger Project-The Learning Child-with the aim of generating research-based knowledge of children's development from the ages of $2 \frac{1}{2}-10$ years. In toddler-age and preschool-age the children's language, mathematics, motor and social-emotional development are the main focus, and their reading, writing and arithmetic skills are the focus when they are in school. Over 1000 children have participated in the project.

\subsection{Participants}

The participants in the present study were 1088 toddlers (532 girls, 556 boys), aged 33 months, included in the Stavanger Project, of whom we have data for both mathematics and play at this age level. The children attended 86 ECECs, both public and private. Law nationally regulates ECECs and the national curriculum guidelines for ECECs must be applied throughout the country. We consider the city of Stavanger as representative of other Norwegian cities and urban settlements of a certain size in terms of ECEC services.

Notably, $17.6 \%$ of the participants in the present study were multilingual. In the Stavanger municipality, where the 
study was conducted, $22.2 \%$ of the citizens are immigrants or children of immigrants; the average in Norway is $17.7 \%$. The parents were asked about which languages were spoken at home when they gave permission for the child to participate in the study. The parents were not asked about ethnicity since such information is seen as sensitive in Norway and requires extended permission from the Norwegian Social Science Data Services.

Parents' education levels were used as a measurement of the socio-economic status (SES) and data were collected through a questionnaire. Both parents were asked to indicate their highest level of education achieved, by selecting one of four levels. The levels were secondary school, upper secondary school, some college (1-3 years), and college/university degree (more than 3 years). All the parents received the questionnaire, but not all parents returned a completed questionnaire. Therefore, SES data were available only for 419 of the participants (38.5\%) in this study (412 answers for both the mother's and father's education levels, six with answers for only the mother's education level and one with an answer for only the father's education level). The results are presented in Table 1 .

As shown in Table 1, the SES level for the participants in the present study for whom SES data were available is much higher than the education level both in Stavanger in general and in Norway. Several factors may explain the SES gap and our sample may have included families with a higher level of education, or the parents with the highest education levels in our sample understood the importance of answering the questionnaire. The percentage of parents of multilingual children who answered the questionnaire was $35.6 \%$, similarly to the percentage of parents of all children who answered the questionnaire, and thus this group is represented in the same manner as the other groups.

A $t$ test between the groups with and without SES data did not reveal a significant difference between the scores in mathematics (MIO-total) for the group with available SES data $(M=31.31, S D=10.77)$ and the group without available SES data $(M=30.48 ; S D=10.96) ; t(1086)=1.22, p=.22$ (two-tailed). Although the participants in the group without SES data may have had a lower SES, this difference did not appear to interfere with the results.

\subsection{Instruments}

The children's skills in mathematics were assessed using the observation material MIO (Davidsen et al. 2008). ALLE MED (Everyone Included; Løge et al. 2015) was used to assess the children's play skills. Natural situations and children's play activities are recommended as the main observational areas. Both materials were developed in Norway and constructed for use in ECECs, and collect data in accordance with the principles of authentic assessment.

\subsubsection{MIO}

The MIO-scheme consisted of six sections (mathematical areas); each including six items (36 items in total):

(1) Mathematical language (Distinguishes between concepts large and small; Knows what is up and what is down; Uses words that describe toys; Follows instructions on placing; Uses words describing relationship between sizes; Shows what is in the middle).

(2) Logical reasoning (Knows what outdoor clothing to put on when it is raining; Tidies toys and puts them in the right places; Can share equally with a friend; Fetches objects needed for an activity; Reasons out what comes first and last when dressing; Knows the difference between what has happened and what is going to happen).

(3) Shape and space (Can point at different parts of the body; Shows that he or she distinguishes between different shapes; Puzzles a jigsaw with 3-4 pieces into a picture; Can by request go to a fixed place in the room; Draws a human body (tadpole); Copies simple figures).

(4) Pattern and order (Places a picture on an identical picture; Is interested in rhythms and movement; Has knowledge about the daily routines; Puts objects in a line according to size; Makes his or her own patterns; Sorts objects according to one characteristic).

(5) Counting and series of numbers (Distinguishes between one and many; Uses number words; Has started pointing and at the same time using number words; Perceives number of objects up to three without having to
Table 1 Parents' highest levels of education compared with the average education level of the municipality and Norway

\begin{tabular}{lllll}
\hline Level of education & $\begin{array}{l}\text { Mother's edu- } \\
\text { cation level } \\
(n=418)\end{array}$ & $\begin{array}{l}\text { Father's edu- } \\
\text { cation level } \\
(n=413)\end{array}$ & In Stavanger & In Norway \\
\hline Secondary school & 1.9 & 1.2 & 21.5 & 25.8 \\
Upper secondary school & 13.9 & 22.8 & 35.2 & 40.1 \\
Some college/university (1-3 years) & 22.7 & 20.6 & 27.1 & 24.1 \\
College/university degree (more than 3 years) & 61.5 & 55.4 & 16.2 & 10.0 \\
\hline
\end{tabular}


count them; Counting to five while correctly pointing at objects; Can recite the number sequence up to ten)

(6) Enumeration (Fetches two objects on request; Can hand out one item to each person; Fetches three objects on request; Shows with the fingers how old he or she is; Sets the table for five persons; Can answer how many there are after having counted five objects)

\subsubsection{ALLE MED}

ALLE MED consists of six sections, addressing the following: play, socio-emotional skills, well-being, everyday activities, sensori-motor skills, and language. Each of these sections includes 15 items (a total of 90 items). Each section has five levels of difficulty, with level 0 as the easiest level and level 4 as the most difficult level (see the next section for a detailed description of the assessment of play skills using ALLE MED).

\subsubsection{Pilot testing of the materials}

The materials had been repeatedly piloted in ECECs, with several hundred children, prior to the Stavanger Project. During the pilot testing of the material, the observations were examined to ensure that they were consistent when a child was observed by two different ECEC teachers; this pilot study was conducted for ALLE MED with 157 children, and for MIO with 90 children. The Wilcoxon signed rank test showed good inter-rater reliability both for ALLE MED and MIO. The calculation of Cronbach's alpha yielded a reliability score of .94 for ALLE MED and .96 for MIO, indicating good internal consistency in both materials.

These data from the piloting were unable to be validated by comparison with data from other assessment material, because there was not any other assessment material for the age groups available in Norwegian that map the same fields as ALLE MED and MIO.

The observation materials MIO and ALLE MED used in the present study were not developed for use in research, but for observation in the ECECs. However, the method is consistent with Norwegian ECEC traditions, which are characterised by a social-pedagogical tradition (Jensen 2009) in which the children's own activities are considered more important than formal, teacher-controlled activities (The Directorate of Education and Training 2017).

\subsubsection{Play variables used in the present study}

Since the pilot testing indicated that items at level 0 would be too easy for the toddlers included in our study, data were collected only from items at levels $1-4$. The Play section then contained twelve items that were included in the present study; in addition, three items regarding play from a socio-emotional skills perspective constituted the variable play activities.

From the Play section:

Level 1: Tries out toys, functional play; emerging pretend play; has a varied play repertoire.

Level 2: Plays with other children; initiates play on his or her own; stays in play.

Level 3: Engages in construction play; is active in pretend play; engages in rule-based play.

Level 4: Gets carried away in pretend play; engages in advanced construction play; shows independence in rulebased play.

And from the Socio-emotional Skills section:

Level 1: Engages in solitary and parallel play.

Level 2: Cope with turn-taking in play.

Level 3: Participates in play such as hide-and-seek.

The items were grouped by content into five different play sections according to types of play (Table 2).

The sorting into play sections (type of play) is based on which items are thematically related, as argued for in the background, and not on which level they are placed in the ALLE MED material. The calculation of Cronbach's alpha for the play items yielded a reliability score of .83, indicating good internal consistency.

The selection of items in the different play sections in ALLE MED does not cover all types of play. For example, rough-and-tumble play was omitted, although this type of play has been reported to be important beginning at 2 years of age (Lindsey 2014). Since boys more frequently engage in R\&T play than girls (Tannock 2011), this type of play may be a source of error in the data.

\subsection{Procedure}

All ECECs in Stavanger were invited to participate, all public and approximately $50 \%$ of the private institutions accepted the invitation, resulting in 86 participating ECECs. The parents were required to sign a written consent form for their child to participate before the child was $2 \frac{1}{2}$ years of age and were able to withdraw their consent at any time. The only criteria to participate were that the child was born in the period from July 2005 to December 2007, and attended an ECEC participating in the Stavanger Project. The staff in the ECECs were trained in methods to perform the observations during the daily life activities, and to employ the observation schemes before the observation period. All observers attended two courses of $3 \mathrm{~h}$ each, one for each scheme, held by the researchers. This training was more extensive than in the piloting of the materials. As a part of the training, 
Table 2 The five types of play skills and the items included in each skill

\begin{tabular}{ll}
\hline Type of play skill & Item \\
\hline 1. Exploring and construction play & Tries out toys, functional play \\
& Engages in construction play \\
Engages in advanced construction play & Emerging pretend play \\
2. Pretend play & Is active in pretend play \\
& Gets carried away in pretend play \\
3. Rule-based play & Engages in rule-based play \\
& Shows independence in rule-based play \\
& Participates in play such as hide-and-seek \\
4. Independence in play & Engages in solitary and parallel play \\
& Initiates play on his or her own \\
5. Interaction in play & Stays in play \\
& Plays with other children \\
& Cope with turn-taking in play \\
& Has a varied play repertoire \\
\hline
\end{tabular}

for the purpose of establishing reliability the staff looked at several examples, both written and in film clips, which they individually marked in the schemes. After marking, they discussed their marking with each other and the researcher responsible for training.

Data regarding the toddlers' skills were observed during play and daily life activities in the ECECs by staff who were familiar with the toddlers. This method for data collection is consistent with the concept of authentic assessment (Bagnato et al. 2014) and is a gentle and non-intrusive approach to obtain data about the children's skills. Authentic assessment provides useful information about the children's levels of functioning, strengths and weaknesses, and provides ecologically valid data (Keilty et al. 2009). Several studies have documented the advantages of authentic assessment compared with standardised assessments, and authentic assessment has become a recommended and accepted practice (Bagnato et al. 2014).

The skills were assessed over a three-month period, from the age of 30 months to the day the toddler turned 33 months of age, to ensure that the skills were observed in different situations and on several occasions. In both schemes, the staff assessed the level of skill acquired by applying a threepoint scale consisting of the categories completely acquired, partially acquired, or not acquired. The assessment material consisted of areas within a circle, one for each of the items to be observed. The area for an item should to be marked completely with a pen or a pencil when the child showed competence in all situations. When the child was beginning to show competence, in some situations, or with help from staff, the area was filled with stripes. When competence had not yet been observed by the staff, the area was not filled in.

Detailed descriptions of each item in the registration forms and directions for scoring were developed to facilitate data collection by the staff and increase the reliability of the data collection procedure (Mellegaard et al. 2006; Davidsen et al. 2008). The time of observation was not standardised. The staff were asked to pay attention to all items for all the children. For some children it was easy to fill out, whereas for others more time was needed for observation. The staff had the possibility of observing the child over a 3 months period and most of them did it in several rounds through this timeslot, just to be sure.

All observations were required to be independently conducted by two staff members. Both in the training and in written information to the staff, it was underlined that if the two observers did not totally agree, they should observe the child in other situations. If they did not agree after that, either another pedagogue (most commonly the pedagogical leader of the ECEC) should also observe the child. This procedure strengthened the reliability of the results.

When the observations were completed, the observation forms were returned to the researchers for coding and statistical analysis.

\subsection{Data coding}

The results were coded as follows: two points for a completely acquired skill, one point for a partially acquired skill, and zero points for children who had not yet acquired the skill. This system enables a possible maximum score of 72 points for all items in the MIO, i.e., 12 points for each of the six sections (mathematical areas). For the Play section with 15 items, the maximum score was 30 points with a maximum of 6 points for each of the play sections (types of play skills).

\subsection{Analysis}

The statistical analyses were performed using the Statistical Package of the Social Science (SPSS) version 21.9 (IBM-Corporation, 2013). Two research assistants entered 
the data into an SPSS file, one read up the results from the scheme and the other entered. When data from a scheme were entered, the one who had entered the data read them aloud and the other controlled it in the scheme. In addition, data for $10 \%$ of the participants were randomly selected and the data were entered a second time to compare the degree of deviation. This control procedure revealed good consistency (>90\%) between the datasets. In addition, frequency analyses were performed for each of the variables to verify whether the values were within the range of possible values. Very few deviations were discovered and these were corrected in the dataset.

Parametric statistics, such as the Pearson product-moment correlation coefficient, require a normal distribution of data. A visual assessment of the shape of the distribution curve is the preferred method for evaluating deviations from normality in larger samples, as the standard error and skewness will decrease as N increases (Tabachnick and Fidell 2014). According to the Q-Q plots, neither the data for MIO nor for the Play variable from ALLE MED exhibited a significant deviation from a normal distribution, and the Pearson product-moment correlation coefficients were calculated to examine the strength of the relations between play skills and mathematical skills. The Q-Q plots of the scores for the sections examining play skills and mathematical skills showed distributions near normal, except for rule-based play, which probably was caused by its low mean value.

Correlation with high $N$ have been criticised due to the presence of false results. However, there is a lack of guidelines in relation to research on toddlers. Therefore, to strengthen the study, also the relation between level of play skill and how it is related to mathematical skills was explored. The toddlers were divided into the following three groups of approximately the same size, based on three levels of scores for play, namely, weak play skills, middle play skills and strong play skills. Descriptive statistical analyses (mean and standard deviation) for the total score on MIO and the mathematical areas in MIO were performed for these three groups. A one-way between groups analysis of variance (ANOVA) was applied to examine whether the three groups differed significantly in their mean scores for both total MIO and the mathematical areas. Bonferroni corrections was applied to the analysis of the three groups to prevent a Type I error. This analysis was used although the same variance in the groups was not expected, since an ANOVA is not substantially dependent on an assumption of equal variance in compared groups (Norušis 2010).

\subsection{Ethical considerations}

The study was approved by the Norwegian Social Science Data Services and was conducted in accordance with the ethical regulations for research in Norway. Participation was based on the parents' voluntary and written consent and the participant's anonymity was ensured. The application of an authentic assessment is a respectful methodological approach.

\section{Results and discussion}

The aim of the present study was to analyse the relationship between play skills and mathematical skills in toddlers, by examining the correlations between overall scores, the scores for different kinds of play skills and mathematical skills, and how level of play skills is related to mathematical skills.

\subsection{Correlations between play skills and mathematical skills}

To explore the correlations between mathematical skills and play skills Pearson product-moment correlation coefficients were calculated both between the total score for mathematical skills (MIO total) and the total scores for play skills, and between the scores for different play sections and the different sections in MIO (Table 3).

The correlations between Total Play skills and MIO-total are as also the correlations between Total Play skills and four of the mathematical areas (Mathematical language, Logical reasoning, Shape and Space and Pattern and Order) strong. For Counting and Series of Numbers and Enumeration, the correlations were moderate, but in the upper range. These results indicate that when the toddlers' play skills were summed to a total score, they were relatively strongly correlated with skills in all the mathematical areas.

When it was examined whether any particular type of play skill in toddlers displayed greater correlations with mathematical skills than others, correlations were found between the MIO-total and that for all play skills, and all play sections correlated with all the mathematical sections in the MIO.

Two of the correlations between MIO-total and the play sections were strong (Independence in play and Interaction in play), and the other correlations were of moderate strength. Most of the correlations (22) between the different play skills and mathematical skills were of moderate strength.

The correlations between the play section Exploring and construction play and the mathematical skills were all moderate, similarly to the correlation between the totalMIO and this play skill. The toddlers' need for sensorimotor experiences in order to learn mathematics is well established (Solem and Reikerås 2017), and this relation was not surprising. In particular, relations with the geometrical areas Shape and Space and Pattern and Order was expected, since 


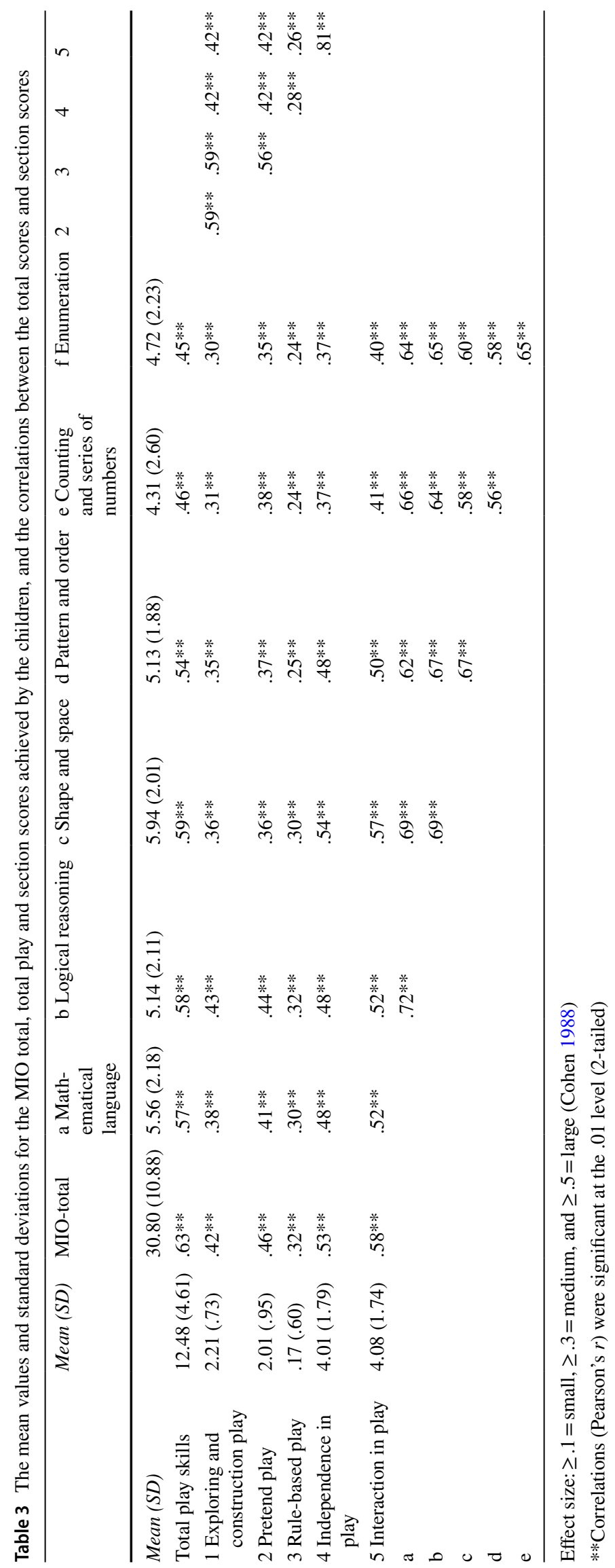


these relations were reported in a previous study (Casey et al. 2008). Play with building blocks has also been reported to be linked to increased skills in mathematical language and numeracy (Schmitt et al. 2018). The results in the present study identified even stronger relations between skills in Exploring and construction play and Mathematical language and Logical reasoning than the correlations with the geometrical areas. The weakest correlations with the present play section were observed for two quantitative areas, Counting and Series of Numbers and Enumeration, where the correlations were near being weak. Nevertheless, these mathematical areas correlate with Exploring and construction play, and these correlations may depend on age, since the participants in the present study were toddlers, whereas earlier findings (e.g., Schmitt et al. 2018) were obtained from somewhat older children (pre-schoolers).

The play section Pretend play and the sum of mathematical scores (MIO-total) exhibited a moderate (near strong) correlation. The mathematical areas exhibiting the strongest correlations with this play section were Mathematical language and Logical reasoning. This finding is consistent with the clear links identified between language development and the development of pretend play, as well as between pretend play and problem solving (Bergen 2002). Although the toddlers were in the beginning stages of the development of pretend play (Hännikäinen and Munter 2018), relations to the mathematical areas described above were also present at a moderate strength. Lillard et al. (2013) asked for more evidence of the impact of pretend play on cognitive development. The present study is unable to show causality; however, the results show a relation between mathematical skills and skills in pretend play. This finding supports the theory proposed by Lillard et al. known as the "claim about the relations" that was initially argued for by Vygotskij (1978).

Rule-based play is difficult for the toddlers, which is shown in Table 3 through the comparison of the mean scores for Rule-based play and the other play sections. The low mean score for Rule-based play skills (.17) makes it little meaningful to analyse the correlations with mathematical skills and rule-based skills, as the lowest correlation was observed between these play skills and mathematical skills. Rule-based play in the form of games is often used to stimulate mathematical development in older children (Mononen et al. 2014). The low level of correlations identified between rule-based play and mathematical skills in the present study implies that other types of play may be better suited in the work with toddlers to foster mathematics skills.

Although children's play was categorised in different types of play and play skills in the present study, these categories are not strictly separated. For example, pretend play is often present in block play, and the children establish rules for pretend play. The intercorrelations between the three specific play skills (see Table 3 ) also support this hypothesis by showing strong correlations between all of the following skills: Exploring and construction play and Pretend play, Exploring and construction play and Rule-based play, and between Pretend play and Rule-based play. In addition, the toddlers alternate smoothly between different types of play, and therefore more than one play type may be present over short timeslots (Hännikäinen and Munter 2018).

The last two Play skill areas, Independence in play and Interaction in play, are more general skills than the play skills related to specific types of play. These two skills are the Play skill areas with the highest mean and the largest correlations both with the MIO-total and with the mathematical areas, supporting the hypothesis that these skills are more general skills required for toddlers to learn. Four of the correlations between mathematical skills and Interaction in play were strong, and one of the correlations in Independence in play was strong. Three of the remaining correlations were in the upper range of the moderate category. The abilities to be active in solitary play and parallel play, as well as to initiate play (two of the three items in the Independence of Play section) show that the toddler wants to explore his or her surroundings, which is very important for learning mathematics (Solem and Reikerås 2017) and may explain some of the relations found in the present study. The toddlers' ability to stay in play (the third item within the Independence in Play category) mirrors the toddlers' selfregulation skills, which are related to the level of activity of children in play and their academic skills, such as mathematics (Becker et al. 2014). This may explain the relatively high correlations found between Independence in Play and the mathematical skills.

The play section displaying the highest correlation with the total score for mathematical skills was Interaction in play. This correlation confirmed previous findings describing the importance of social interaction for children's learning of mathematics. During play with other children, which is one of the items in this play section, children often take turns (a second item). Turn-taking requires both self-regulation (which is related to mathematical skills) and an understanding of order. Children with a varied play repertoire (the third item) are more often popular play-mates and participate more frequently in interplay than children with a more limited play repertoire (Stangeland 2017).

The mathematical areas exhibiting the highest correlation with Independence in Play and Interaction in Play were Shape and Space, Mathematical Language, Logical Reasoning and Pattern and Order. Five of these correlations were large, and the remaining correlations were in the upper range of moderate. The remaining correlations with Counting and Series of Numbers and Enumeration were all moderate. Why the correlations between these two more general play skills and the quantitative areas were somewhat lower than the other areas is not known. For most play skills, the pattern 
with the lowest correlations were quantitative skills, the only exception was the correlation between Pretend Play and Counting and Series of Numbers, which was greater than the correlation between Pretend Play and the two geometrical areas.

Table 3 also shows the intercorrelations between the play skills and between the mathematical skills. The correlation between Independence in play and Interaction in play was high (.81) and may indicate that these skills measure a similar general social play skill. The correlations between the three types of play, namely, Exploring and construction play, Pretend play and Rule-based play, were also high, indicating that these skills also possess strong relationships. The relations between the two general play skills and the three different types of play skills were low to moderate. The intercorrelations between the mathematical skills were generally high, and only two were of medium strength, indicating that the MIO measures an overall level of mathematical skills, consistent with a previous report (Reikerås et al. 2012). Consequently, the findings of the correlations between the different types of mathematical skills and play skills should be interpreted with caution.

\subsection{Levels of play skills and mathematical skills}

The relations between the levels of play skills and mathematical skills were further examined by comparing the mathematical skills of groups with different levels of play skills. The total sample was divided into three groups based on the children's results on the assessment of Play skills (weak, moderate and strong play skills), and each group included approximately one-third of the total sample. We accepted some differences in the group size to include all children with a certain test score in the appropriate group. The scores used for grouping and results of the play skills in ALLE MED and for MIO for the total sample and for each of the groups are presented in Table 4.

As hypothesised, ANOVA revealed significant differences in the total score for the Play skills between the groups
$F(2,1085)=2522.71, p<.01$. A Bonferroni correction was applied to prevent a Type I error. The significance level of .05 was divided by three and thus the significance level was adjusted to .017 . The effect size eta square was .82 and considered large (Cohen 1988). The Bonferroni post hoc test showed that this result applies to all differences between weak, moderate and strong groups $(p<.01)$. Based on these results, the criteria selected for creating the groups were efficient.

Possible differences in mathematical skills between the groups with weak, moderate and strong play skills were explored using ANOVA. As above, the significance level was adjusted to .017 . The statistically significant difference at $p<.017$ was found for MIO-total $F(2,1085)=293.52$, $p<.001$. The effect size, eta squared, was .35 and considered large according to Cohen (1988).

The Levene's Test of Equality of Variances shows a violation of the homogeneity of variance $(p<.05)$ both for the total score of Play skills and MIO total. As argued in the method section, ANOVA was still relevant and was used. To be sure violating the assumption of homogeneity did not give a falsely significant result, a Welch Robust test of Equality of means was performed and showed significant differences $(p<.01)$ between the groups in line with the ANOVA.

The post hoc tests (Bonferroni) revealed that the differences between the mean scores were statistically significant $(p<0.01)$ for all differences between the groups. The effect size (Cohen's d) was calculated to evaluate the importance of these differences between the groups (Cohen 1988). The largest effect on mathematical skills of groups formed according to the level of play skills was found between the weak group and the strong group, where Cohen's $d$ was 1.78, and according to Sawilowsky (2009), this effect was very large $(1.20 \leq$ Cohen's $d)$. Cohen's $d$ was .91 and .83 for the comparisons between the groups with weak and moderate play skills and between the groups with middle and strong play skills, respectively, which are considered large effects $(0.80 \leq$ Cohen's $d<1.20)$ (Sawilowsky 2009).
Table 4 Play skills (sum of 15 items in ALLE MED) and mathematical skills (MIO-total) for the total sample and the groups with weak play skills, moderate play skills and strong play skills

\begin{tabular}{|c|c|c|c|c|}
\hline & $\begin{array}{l}\text { Total sample } \\
(n=1088)\end{array}$ & $\begin{array}{l}\text { Weak play skills* } \\
(n=366)\end{array}$ & $\begin{array}{l}\text { Moderate play } \\
\text { skills* } \\
(n=320)\end{array}$ & $\begin{array}{l}\text { Strong play skills* } \\
(n=402)\end{array}$ \\
\hline \multicolumn{5}{|c|}{ Total play skills } \\
\hline Mean & 12.48 & 7.27 & 12.48 & 17.23 \\
\hline SD & 4.61 & 1.54 & 1.39 & 2.55 \\
\hline $\operatorname{Min} / \max ^{\mathrm{a}}$ & $0 / 30$ & $0 / 9$ & $10 / 14$ & $15 / 30$ \\
\hline \multicolumn{5}{|l|}{ MIO total } \\
\hline Mean & 30.80 & 22.85 & 30.58 & 38.21 \\
\hline SD & 10.80 & 7.94 & 9.06 & 9.27 \\
\hline
\end{tabular}


The group with moderate play skills also achieved a mean MIO-total score (30.58) similar to the mean score achieved by all participants (30.80), indicating that the children's play skills were distributed in a similar manner to the mathematical skills. This finding supports a linear relation between play and mathematics, as was also observed in the correlations presented in Table 3.

These findings indicate a relatively strong relationship between the level of play skills and the level of mathematical skills among toddlers. Thus, this imply that the large correlations found between MIO-total and total Play were not the results of strong correlations only for some parts of the groups of toddlers or of many participants. Weak play skills imply weak mathematical skills, moderate play skills imply moderate mathematical skills and strong play skills imply strong mathematical skills.

\subsection{Limitations}

The large number of people collecting the data might be a limitation of the study. In addition to the training of the staff the reliability could by further strengthened by letting the two observers deliver independent observations. However, the discussion between the observers when seeking agreement contributed to increasing their competence.

The missing SES data should be noted when generalising data, and this is a limitation of the study, although there were not found any differences in mathematical skills between the group with available SES and the group without available SES.

Although the ECECs in Norway are all well equipped, there is not any standardization of what toys they should have. The toddler's access to play material (blocks, etc.) during the observations was not assessed and could influenced the results. Neither is there information from the parents about children's play preferences or previous experience with materials such as blocks at home. This lack of information is also a limitation.

There are no data on whether the observations in the present study were recorded during children's free play, teacher-initiated play or mutual play. This limitation should be accounted for in further research.

\subsection{Contributions and pedagogical consequences}

The present study contribute with new knowledge about the relations between play skills and mathematical skills in toddlers. The large sample size makes the results more generalizable than studies of smaller samples.

The close relations between the toddlers' play skills and mathematical skills found in the present study have consequences for practice in the ECECs working with toddlers. The findings supports the hypothesis that play and learning should be viewed as related skills, and that the toddlers' play should be the central focus when teachers are working with mathematics in toddler groups. Previous studies support the use of a combination of play approaches such as free play, teacher-initiated play or mutual play, when supporting young children's learning of mathematics (Salomonsen 2019).

Regarding different play skills, Interaction in Play and Independence in Play are both more important play skills in toddlers and display the strongest correlations with mathematical skills than the play skills related to specific play types. Few toddlers master Rule-based Play, whereas Pretend Play and Exploring and Construction Play may be play forms that are more suitable for the work with this age group. These two types of play exhibit somewhat higher correlations with mathematics than Rule-based play. The types of play may be related to mathematical skills in other ways when the children are older. More comprehensive studies are needed to follow the children's play skills and determine how they correlate with different types of mathematical skills.

The findings that the levels of play skills imply the same levels of mathematical skills underscore the importance of considering the toddlers' play when planning for and implementing mathematical activities in the ECECs. In particular, the play skills of children with weak play skills must be strengthened to help the toddlers develop the tools required for exploring, playing and learning.

The present study is unable to establish conclusions about causality, and more research is needed to determine how different kinds of play skills that develop at an early age predict mathematical skills at older ages. Mathematical skills might also be important for development of play skills, which needs to be explored in further research. As the present study is part of the longitudinal Stavanger Project-The Learning Child, longitudinal data are available for these analyses.

Acknowledgments Open Access funding provided by University Of Stavanger.

Open Access This article is licensed under a Creative Commons Attribution 4.0 International License, which permits use, sharing, adaptation, distribution and reproduction in any medium or format, as long as you give appropriate credit to the original author(s) and the source, provide a link to the Creative Commons licence, and indicate if changes were made. The images or other third party material in this article are included in the article's Creative Commons licence, unless indicated otherwise in a credit line to the material. If material is not included in the article's Creative Commons licence and your intended use is not permitted by statutory regulation or exceeds the permitted use, you will need to obtain permission directly from the copyright holder. To view a copy of this licence, visit http://creativecommons.org/licenses/by/4.0/. 


\section{References}

Bagnato, S., Goins, D., Pretti-Frontczak, K., \& Neisworth, J. T. (2014). Authentic assessment as "best practice" for early childhood intervention: National consumer social validity research. Topics in Early Childhood Special Education, 34(2), 116-127.

Becker, D. R., McClelland, M. M., Loprinzi, P., \& Trost, S. G. (2014). Physical activity, self-regulation, and early academic achievement in preschool children. Early Education and Development, 25(1), $56-70$.

Bergen, D. (2002). The role of pretend play in children's cognitive development Early Childhood Research and Practice, 4(1). Retrieved from https://files.eric.ed.gov/fulltext/ED464763.pdf.

Björklund, C. (2008). Toddlers' opportunities to learn mathematics. International Journal of Early Childhood, 40(1), 81-95.

Bodrova, E., \& Leong, D. J. (2015). Vygotskian and post-Vygotskian views on children's play. American Journal of Play, 7(3), 371-388.

Bubikova-Moan, J., Hjetland, H., \& Wollscheid, S. (2019). ECE teachers' views on play-based learning: A systematic review. European Early Childhood Education Research Journal, 27,(6), 776-800. https://doi.org/10.1080/1350293X.2019.1678717.

Casey, B. M., Andrews, N., Schindler, H., Kersh, J. E., Samper, A., \& Copley, J. (2008). The development of spatial skills through interventions involving block building activities. Cognition and Instruction, 26(3), 269-309.

Chen, Z., \& Siegler, R. S. (2000). Across the great divide: Bridging the gap between understanding of toddlers' and older children's thinking. Malden, MA: Wiley-Blackwell.

Claessens, A., Duncan, G. J., \& Engel, M. (2009). Kindergarten skills and fifth grade achievement: Evidence from the ECLS-K. Economics of Educational Review, 28, 415-427.

Clements, D. H., Baroody, A. J., \& Sarama, J. A. (2014). Background research on early mathematics. Retrieved from https://www.resea rchgate.net/publication/259575583_Background_research_on_ early_mathematics.

Cohen, J. (1988). Statistical power analysis for behavioural sciences. Hillsdale: Lawrence Erlbaum.

Cohrssen, C., \& Niklas, F. (2019). Using mathematics games in preschool settings to support the development of children's numeracy skills. International Journal of Early Years Education, 27(3), 322-339. https://doi.org/10.1080/09669760.2019.1629882.

Davidsen, H., Løge, I. K., Lunde, O., Reikerås, E., \& Dalvang, T. (2008). MIO, Matematikken, Individet og Omgivelsene. Håndbok. Oslo: Aschehoug.

Engdahl, I. (2011). Toddler interaction during play in the Swedish preschool. Early Child Development and Care, 181(10), 1421-1439.

Engel, S. (2005). The narrative worlds of what is and what if. Cognitive Development, 20(4), 514-525.

English, L. D. (2004). Mathematical and analogical reasoning in early childhood. In L. D. English (Ed.), Mathematical and analogical reasoning of young learners (pp. 1-22). Mahwah, NJ: Lawrence Erlbaum Associates.

Fisher, K., Hirsh-Pasek, K., Golinkoff, R. M., Singer, D. G., \& Berk, L. (2011). Playing around in school: Implications for learning and educational policy. The Oxford handbook of the development of play (pp. 341-360). New York, NY: Oxford University Press.

Fleer, M. (2014). Theorising play in the early years. New York: Cambridge University Press.

Golinkoff, R. M., Hirsh-Pasek, K., \& Singer, D. G. (2006). Play = learning: How play motivates and enhances children's cognitive and social-emotional growth. Oxford: Oxford University Press.
Hännikäinen, M., \& Munter, H. (2018). Toddlers' play in early childhood education settings. In P. K. Smith \& J. L. Roopnarine (Eds.), The Cambridge handbook of play: Developmental and disciplinary perspectives (pp. 491-510). Cambridge: Cambridge University Press.

Hassinger-Das, B., Zosh, J. M., Hirsh-Pasek, K., \& Golinkoff, R. M. (2018). Playing to learn mathematics. In R. E. Tremblay, M. Boivin, \& R. D. Peters (Eds.), Encyclopedia on early childhood development. http://www.child-encyclopedia.com/play-based -learning/according-experts/playing-learn-mathematics.

Henry, M. (1990). More than just play: The significance of mutually directed adult-child activity. Early Child Development and Care, 60(1), 35-51.

Hirsh-Pasek, K., Golinkoff, R. M., Berk, L. E., \& Singer, D. G. (2009). A mandate for playful learning in preschool. New York: Oxford University Press.

IBM Corporation. (2013). IBM SPSS statistics for Windows, Version 21. Armonk, NY: IBM Corporation.

Jensen, B. (2009). A Nordic approach to early childhood education (ECE) and socially endangered children. European Early Childhood Education Research Journal, 17(1), 7-21.

Jing, M., \& Li, H. (2015). Effect of partner's gender on early pretend play: A preliminary study of Singapore Chinese preschoolers. Early Child Development and Care, 185(8), 1216-1237.

Keilty, B., LaRocco, D. J., \& Casell, F. B. (2009). Early interventionists' reports of authentic assessment methods through focus group research. Topics in Early Childhood Special Education, 28(4), $244-256$

Lai, N. K., Ang, T. F., Por, L. Y., \& Liew, C. S. (2018). The impact of play on child development-A literature review. European Early Childhood Education Research Journal, 26(5), 625-643.

Lillard, A. S. (1993). Pretend play skills and the child's theory of mind. Child Development, 64(2), 348-371.

Lillard, A., Lerner, M., Hopkins, E., Dore, R., Smith, E., \& Palmquist, C. (2013). The impact of pretend play on children's development: A review of the evidence. Psychological Bulletin, 139(1), 1.

Lindsey, E. W. (2014). Physical activity play and preschool children's peer acceptance: Distinctions between rough-and-tumble and exercise play. Early Education and Development, 25(3), 1-18.

Løge, I. K., Leidland, K., Mellegaard, M. R., Olsen, A. H. S., \& Waldeland, T. (2015). Alle med : håndbok. Bryne: Infovest forl.

MacDonald, A., \& Murphy, S. (2019). Mathematics education for children under four years of age: A systematic review of the literature. Early Years. https://doi.org/10.1080/09575146.2019.1624507.

Manning, M. M., \& Wainwright, L. D. (2010). The role of high level play as a predictor social functioning in autism. Journal of Autism and Developmental Disorders, 40(5), 523-533.

Meland, A. T., Kaltvedt, E., \& Reikerås, E. (2019). Toddlers play in ECEC-institutions in a gender perspective. European Early Childhood Education Research Journal., 27(2), 241-256.

Mellegaard, M., Waldeland, T., Leidland, K., \& Olsen, A. H. S. (2006). Presisering av utsagn i Alle Med. Stavanger: Lesesenteret, Universitetet i Stavanger.

Mix, K. S., Huttenlocher, J., \& Levine, S. C. (2002). Quantitative development in infancy and early childhood. Oxford: Oxford University Press.

Mononen, R., Aunio, P., Koponen, T., \& Aro, M. (2014). A review of early numeracy interventions for children at risk in mathematics. International Journal of Early Childhood special Education, 6, $25-54$.

Montford, E. I. P., \& Readdick, C. A. (2008). Puzzlemaking and partwhole perception of two-year-old and four-year-old children. Early Child Development and Care, 178(5), 537-550.

Norušis, M. J. (2010). PASW statistics 18: Guide to data analysis. Upper Saddle River, NJ: Prentice Hall. 
Ødegaard, E., \& Hu, A. (2019). Play and/or learning: Comparative analysis of dominant concepts in national curriculum guidelines for early childhood education in Norway, Finland, China, and Hong Kong. Annual Review of Comparative and International Education. https://doi.org/10.1108/S1479-367920190000037016.

Pellegrini, A. D., Dupuis, D., \& Smith, P. K. (2007). Play in evolution and development. Developmental Review, 27(2), 261-276. https ://doi.org/10.1016/j.dr.2006.09.001.

Ramani, G. B., Daubert, E. N., \& Scalise, N. R. (2019). Chapter 3. Role of play and games in building children's foundational numerical knowledge. In D. C. Geary, D. B. Berch, \& K. Mann Koepke (Eds.), Cognitive foundations for improving mathematical learning (Vol. 5, pp. 69-90). New York: Academic Press.

Ramani, G. B., \& Scalise, N. R. (2020). It's more than just fun and games: Play-based mathematics activities for head start families. Early Childhood Research Quarterly. https://doi.org/10.1016/j. ecresq.2018.07.011.

Reikerås, E., Løge, I., \& Knivsberg, A.-M. (2012). The mathematical competencies of toddlers expressed in their play and daily life activities in Norwegian kindergartens. International Journal of Early Childhood, 44(1), 91-114.

Salomonsen, T. (2019). What does the research tell us about how children best learn mathematics? Early Child Development and Care. https://doi.org/10.1080/03004430.2018.1562447

Samuelsson, I. P., \& Carlsson, M. A. (2008). The playing learning child: Towards a pedagogy of early childhood. Scandinavian Journal of Educational Research, 52(6), 623-641.

Samuelsson, I. P., \& Johansson, E. (2006). Play and learning-Inseparable dimensions in preschool practice. Early Child Development and Care, 176(1), 47-65.

Sarama, J. A., \& Clements, D. H. (2009). Early childhood mathematics education research: Learning trajectories for young children. New York: Routledge.

Sawilowsky, S. S. (2009). New effect size rules of thumb. Journal of Modern Applied Statistical Methods, 8(2), 597-599.

Schmitt, S. A., Korucu, I., Napoli, A. R., Bryant, L. M., \& Purpura, D. J. (2018). Using block play to enhance preschool children's mathematics and executive functioning: A randomized controlled trial. Early Childhood Research Quarterly, 44, 181-191.

Seo, K., \& Ginsburg, H. P. (2004). What is developmentally appropriate in early childhood mathematics education? Lessons from new research. In D. H. Clements, J. A. Sarama, \& A.-M. DiBiase (Eds.), Engaging Young Children in Mathematics. Mahwah: Lawrence Erlbaum Associates.

Solem, I. H., \& Reikerås, E. (2017). Det matematiske barnet (The mathematical child) (3rd ed.). Landås: Caspar.
Stangeland, E. B. (2017). The impact of language skills and social competence on play behaviour in toddlers. European Early Childhood Education Research Journal, 25(1), 106-121.

Storli, R., \& Sandseter, E. B. H. (2015). Preschool teachers' perceptions of children's rough-and-tumble play (R\&T) in indoor and outdoor environments. Early Child Development and Care, 185(11-12), 1995-2009. https://doi.org/10.1080/03004430.2015.1028394.

Sundsdal, E., \& Øksnes, M. (2015). Til forsvar for barns spontane lek. Nordisk tidsskrift for pedagogikk og kritikk, 1. https://doi. org/10.17585/ntpk.v1.89.

Sutton-Smith, B. (2009). The ambiguity of play (New ed.). Cambridge, MA: Harvard University Press.

Synodi, E. (2010). Play in the kindergarten: The case of Norway, Sweden, New Zealand and Japan. International Journal of Early Years Education, 18(3), 185-200.

Tabachnick, B. G., \& Fidell, L. S. (2014). Using multivariate statistics. Harlow: Pearson.

Tannock, M. (2011). Observing young children's rough-and-tumble play. Australasian Journal of Early Childhood, 36(2), 13-20.

The Directorate of Education and Training. (2017). Regulations on the framework plan for the kindergarten's content and tasks. Retrieved from https://www.udir.no/globalassets/filer/barnehage/ rammeplan/framework-plan-for-kindergartens2-2017.pdf.

Vogt, F., Hauser, B., Stebler, R., Rechsteiner, K., \& Urech, C. (2018). Learning through play-Pedagogy and learning outcomes in early childhood mathematics. European Early Childhood Education Research Journal, 26(4), 589-603.

Vygotskij, L. S. (1978). Mind in society. The development of higher psychological processes. Cambridge, MA: Harvard University Press.

Wood, E. (2010). Developing integrated pedagogical approaches to play and learning. In P. Broadhead, J. Howard, \& E. Wood (Eds.), Play and learning in the early years (pp. 9-24). London: Sage.

Wood, E. (2013). Play, learning and the early childhood curriculum (3rd ed.). Los Angeles, CA: Sage Chapman.

Worthington, M., \& van Oers, B. (2016). Pretend play and the cultural foundations of mathematics. European Early Childhood Education Research Journal, 24(1), 51-66.

Publisher's Note Springer Nature remains neutral with regard to jurisdictional claims in published maps and institutional affiliations. 